\title{
ZERO BOIL-OFF SYSTEM TESTING
}

\author{
D.W. Plachta ${ }^{1}$ and W.L. Johnson ${ }^{1}$, J.R Feller ${ }^{2}$ \\ ${ }^{1}$ NASA Glenn Research Center \\ ${ }^{2}$ NASA Ames Research Center
}

\begin{abstract}
Cryogenic propellants such as liquid hydrogen $\left(\mathrm{LH}_{2}\right)$ and liquid oxygen $\left(\mathrm{LO}_{2}\right)$ are a part of NASA's future space exploration plans due to their high specific impulse for rocket motors of upper stages. However, the low storage temperatures of $\mathrm{LH}_{2}$ and $\mathrm{LO}_{2}$ cause substantial boil-off losses for long duration missions. These losses can be eliminated by incorporating high performance cryocooler technology to intercept heat load to the propellant tanks and modulating the cryocooler temperature to control tank pressure. The technology being developed by NASA is the reverse turbo-Brayton cycle cryocooler and its integration to the propellant tank through a distributed cooling tubing network coupled to the tank wall. This configuration was recently tested at NASA Glenn Research Center in a vacuum chamber and cryoshroud that simulated the essential thermal aspects of low Earth orbit, its vacuum and temperature. This test series established that the active cooling system integrated with the propellant tank eliminated boil-off and robustly controlled tank pressure.
\end{abstract}

\section{Introduction}

To expand human presence into the solar system and onto the surface of Mars, NASA is considering high-specific-impulse propellant combinations, such as $\mathrm{LH}_{2}$ and $\mathrm{LO}_{2}$, for orbiting depots, orbit transfer stages, and for Mars surface. However, for volumetric considerations, cryogenic propellants are stored as liquids at extremely low temperatures. The heat radiated to the spacecraft from both the Sun and any other celestial body the spacecraft may be near (such as Earth, the moon, Mars, etc.) and heat conducted down to the storage tanks from other sources on the spacecraft cause $\mathrm{LH}_{2}$ and $\mathrm{LO}_{2}$ to pressurize and boil off (change state from liquid to gas). If this is left to its own devices, the storage tanks will over-pressurize; thus they must vent some of the vaporized liquid, resulting in less propellant remaining available for propulsion. Because mission architecture loiter periods are projected to be months long [1], the vented vapor losses will be substantial. To allow for these losses during the long space missions envisioned, the stage would need to carry excess propellant which would be very heavy. Alternatively, NASA could use thick walled propellant tanks that operate at high pressure, but the additional mass of the heavier tanks would also be prohibitive. The application of Zero Boil-Off (ZBO) technology to prevent vaporization and keep storage tanks reasonably sized and low weight will enable missions to store adequate propellant quantities for long periods of time. Development work and testing on this concept using distributive cooling has been 
on going at NASA since 2007, with the Cryogenic Boil-Off Reduction System activities[2],[3],[4]. Analysis of this ZBO concept applied to liquid oxygen tanks predicts that it will reduce mass for missions in low Earth orbit (LEO) that have loiter periods greater than 1 week. [5] The preferred distributed cooling system utilizes the reverse turbo-Brayton cycle cryocooler and the circulator that is inherent to it. This concept and associate technology was demonstrated in a series of 10 tests performed at NASA Glenn Research Center's Small Multi-Purpose Research Facility (SMiRF). Three "passive," with the cryocooler system off, and seven that are "active," with the cryocooler system operational. The test series included tests performed at roughly $90 \%$ full and $25 \%$ full, and demonstrations of cryocooler excess cooling capacity countered with tests at reduced cryocooler capacity. The test series established that the prescribed cryocooler integration system eliminated boil-off and robustly controlled tank pressure.

\section{Objectives}

The purpose of the test was to demonstrate the performance of a flight representative liquid oxygen $\left(\mathrm{LO}_{2}\right) \mathrm{ZBO}$ system. Given the lack of micro-gravity concerns with the active cooling system or on the unvented propellant, this demonstration, prepares the ZBO concept for flight with minor additional development required beyond scaling of components. To achieve this demonstration, three main objectives were identified.

The first objective was to demonstrate robust zero boil-off storage of liquid oxygen. This requires a demonstration of the ability of the active cooling system to control and modulate tank pressure over an extended period of time. Besides achieving $\mathrm{ZBO}$, a demonstration of the active cooling system dropping tank pressure is significant as it indicates the system has performance margin to account for various uncertainties in the design. Inherent in robust $\mathrm{ZBO}$ is the ability to model tank pressurization and depressurization. Because the distributed cooling system in the ZBO design promises to reduce thermal stratification, a simple homogenous model might be accurate. This is planned along with a comparison test, with the cryocooler off, to create a mapping of tank pressure versus net heat removed and added. The second objective was to determine the cryocooler's ability to eliminate boil-off at a low fill level. This is needed for propellant depot or upper stage mission concepts that have multiple transfers or propellant burns that need to be operational at fairly low tank fill levels. Low fill levels increase thermal gradients in the tank and the goal of this second objective is see if the ZBO system can minimize those increased thermal gradients and still maintain tank pressure control and $\mathrm{ZBO}$. The third test objective was to validate the scaling model developed [5, p. 66] that predicts ZBO thermal elements, such as multi-layer insulation (MLI), the cryocooler, radiator, and solar arrays, reduce mass compared to always boiling passive only propellant storage, with MLI only, for loiter periods in LEO of just over one week. Given that this prediction is based on analysis, verification is required to ensure mission architecture consideration of the active cooling concept is done appropriately.

Although the mission architectures are interested in $\mathrm{LO}_{2}$, the high testing costs associated with it caused us to use liquid nitrogen $\left(\mathrm{LN}_{2}\right)$ as a $\mathrm{LO}_{2}$ simulant. A nominal pump fed propulsion system $\mathrm{LO}_{2}$ storage pressure was assumed to be $173 \mathrm{kPa}$ ( $25 \mathrm{psi}$ ), which corresponds to a saturated $\mathrm{LO}_{2}$ temperature of $95.6 \mathrm{~K}$. To accomplish this, the test 


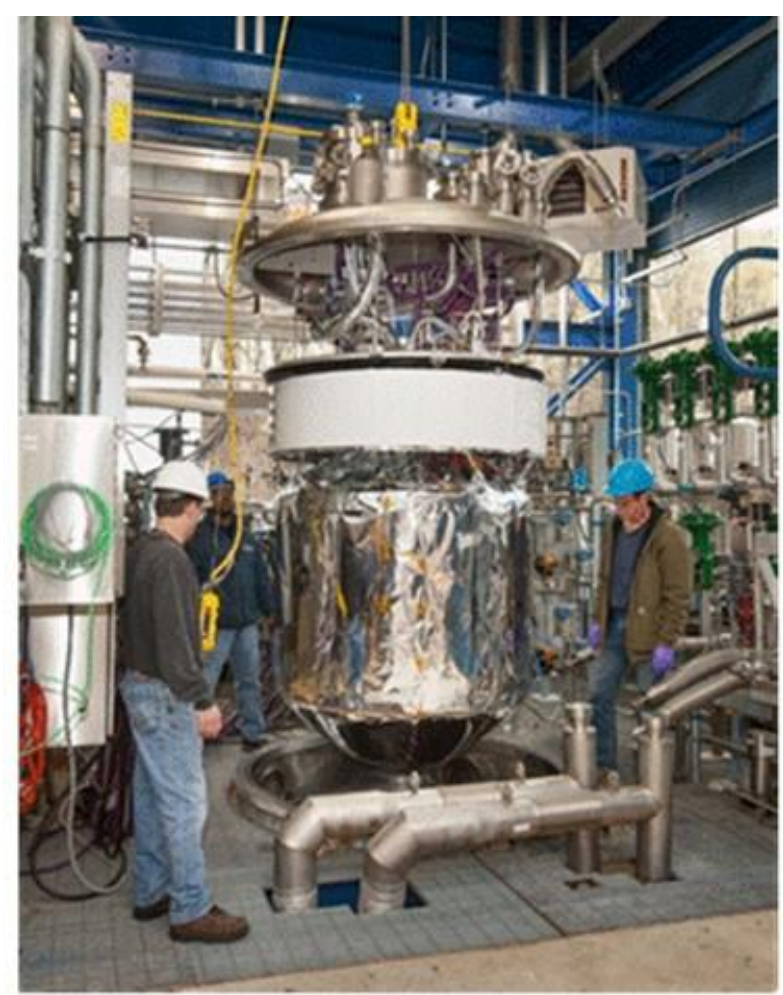

Figure 1. LOX ZBO test article being lowered into the vacuum chamber.

tank was filled with $\mathrm{LN}_{2}$ and pressurized to $565 \mathrm{kPa}$ ( $82 \mathrm{psia}$ ). This is the saturation pressure when $\mathrm{LN}_{2}$ 's saturation temperature $(95.6 \mathrm{~K})$ is equal to that of $\mathrm{LO}_{2}$.

\section{Hardware Description \\ Facility Overview}

The experiment was conducted at NASA GRC's Small Multi-Purpose Research Facility (SMiRF) [6]. SMiRF provided the two main aspects of a LEO simulation test - the vacuum of space and the temperatures of Low Earth Orbit (LEO). The SMiRF facility utilizes a cylindrical vacuum chamber with elliptical heads and achieved an average vacuum of $1 \times 10^{-6}$ torr vacuum throughout the test series. To accurately simulate the space environment, an optically dense flat black painted thermal shroud, or cryoshroud, is fitted closely within the vacuum chamber walls. The cryoshroud is operated as a constant density closed loop $\mathrm{GN}_{2}$ heating/cooling system which was operated at $220 \mathrm{~K}+/-3 \mathrm{~K}$ for 9 of the 10 tests. The shroud reduces the maximum allowable size of the test article to a diameter $1.5 \mathrm{~m}$ and overall length of $2 \mathrm{~m}$. The test article is shown in Figure 1 attached to the vacuum chamber lid at SMiRF and being lowered into the chamber.

\section{Liquid Nitrogen Test Tank}

The test tank is stainless steel with a diameter of $1.2 \mathrm{~m}$ and a $4.7 \mathrm{~mm}$ wall thickness that is $1.2 \mathrm{~m}^{3}$ in volume. The tank height is $1.4 \mathrm{~m}$ and the length to diameter ratio is 1.15 . The 
domes are 2:1 elliptical head domes with a $0.7 \mathrm{~m}$ long cylindrical section in between. The tank was attached to the six struts and via three attachment plates. The struts were $0.38 \mathrm{~m}$ long, having a tapered geometry with a maximum outer diameter of $19 \mathrm{~mm}$ and a 0.82 mm wall thickness. These titanium struts have spherical rod end bearings at both ends.

The tank has twelve heaters attached to its outer diameter at the bottom part of the tank cylinder, which allowed for rapid warm-up of the tank between tests.

The propellant tank maximum operating pressure was $620 \mathrm{kPa}(90 \mathrm{psia})$. The nominal operating pressure was $565 \mathrm{kPa}$ (82 psia).

At the top port of the tank, used for tank venting, a cooling strap was coupled as close to the tank as possible, to reduce the vent line temperature. This was designed and installed because of a pre-test finite element thermal model analysis that indicated a hot spot at the tank top. A model of the tank with the tank penetrations used and all the associated heat leak paths used in the thermal analysis is shown in Figure 2. 


\section{Support Ring}

The support ring is suspended from the SMiRF chamber lid by three cables. The ring supports the tank, the cryocooler, and the radiator and is made from stainless steel. The layout of the components configured in the ring is shown in Figure 3.

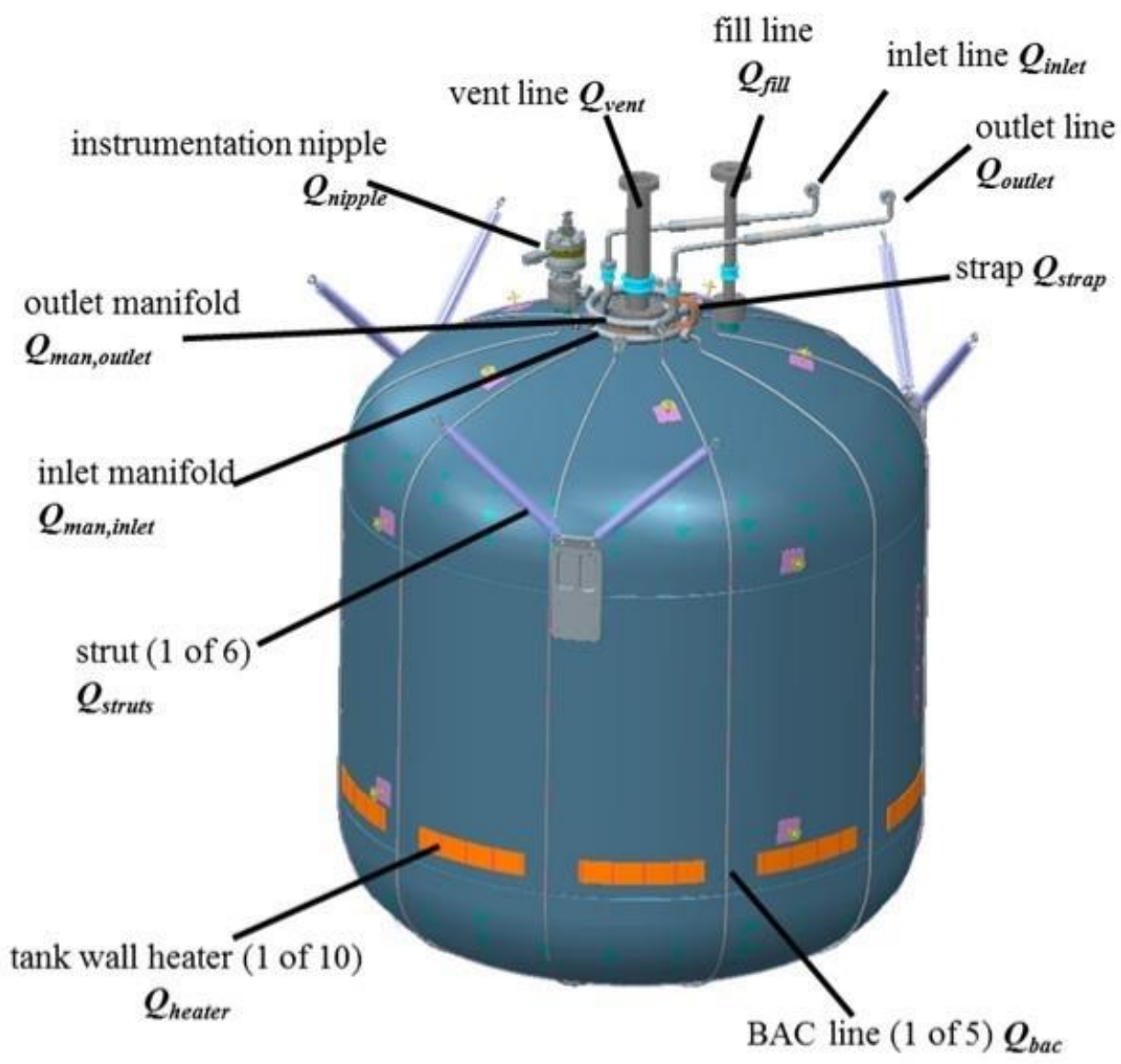

Not shown:

- MLI $Q_{M L I}$

- diode rake $Q_{\text {rake }}$

- capacitance probe $Q_{\text {probe }}$

- instrumentation wiring $Q_{\text {wires }}$

- cryocooler $Q_{c c}$

Figure 2. A 3-D model of the test tank with penetrations and all heat leak paths identified. 


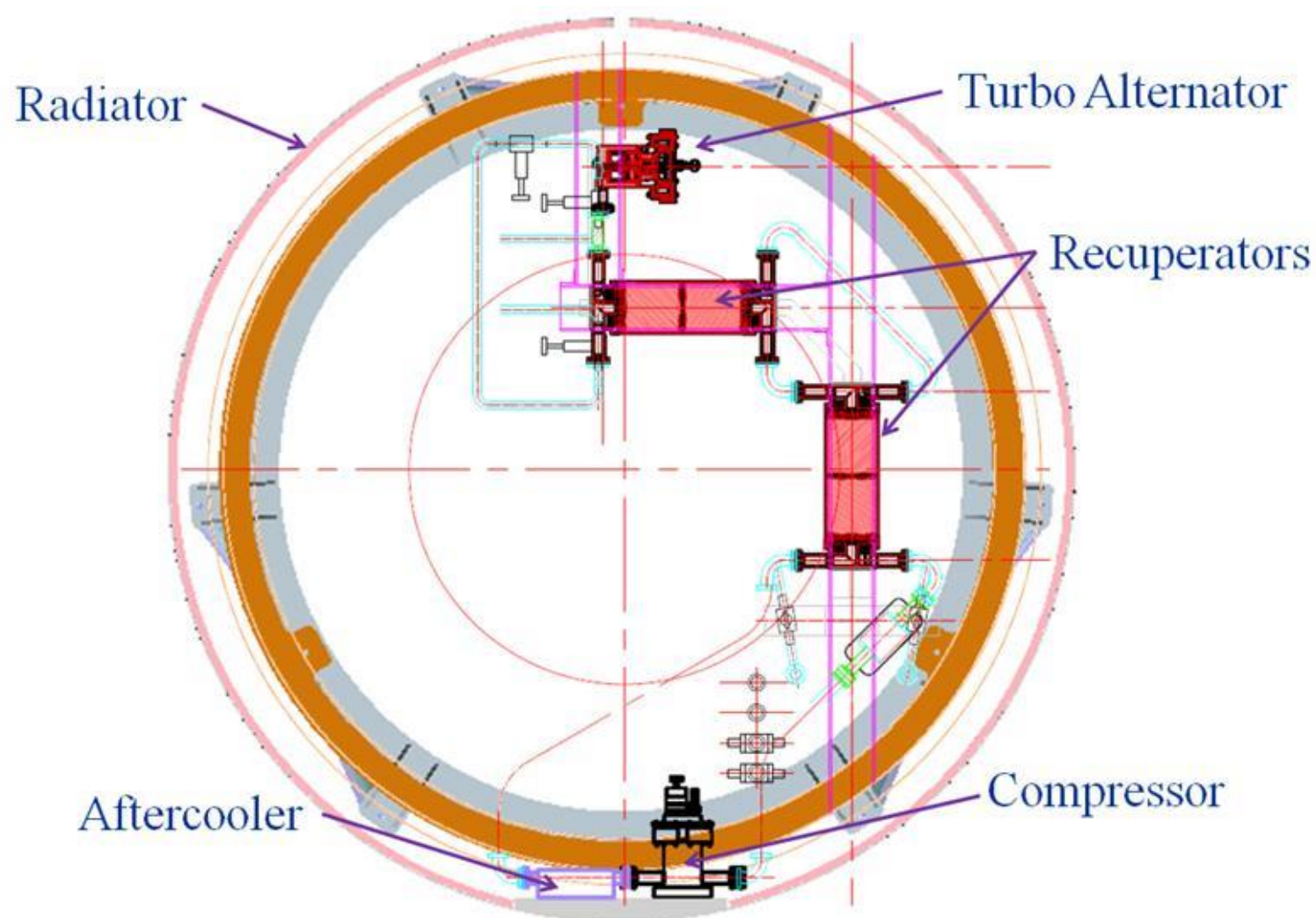

Figure 3. Cryocooler Layout in Support Ring (top view)

\section{Radiator}

The radiator was designed to remove $400 \mathrm{~W}$ of heat at $300 \mathrm{~K}$. It is a curved aluminum panel that is $3 \mathrm{~mm}$ thick. Attached to this panel were four horizontal ammonia heat pipes of $9 \mathrm{~mm}$ diameter. At the end of the radiator panel is the evaporator plate where the cryocooler hot interface was attached. The radiator was insulated with 10 layers of MLI on its inside surface, to ensure that the vast majority of the heat radiates from its outer diameter surface. Its outer surface was painted white with Aeroglaze A276 paint with a measured emissivity was 0.935 .

\section{Insulation}

In order to minimize the heat load on the acreage of the tank, a multilayer insulation system was required. Two MLI blankets were constructed, each with 38 layers (including outer covers) for 75 total reflector layers. The Mylar used was $0.63 \mathrm{~mm}$ ( $0.25 \mathrm{mil})$ double aluminized Mylar (DAM). Each layer was separated by 2 sheets of Dacron B2A polyester netting. The blankets were vented through the seams with a $1 \%$ open area in the outer 2-mil cloth reinforced layer of Mylar. The seams were butted together and adjoined with Mylar (2.5 cm wide) tape every fifth layer. The as built blanket layer density was 24 layers/cm. 
A $12 \mathrm{~mm}$ strip of Cryo-Lite [7] was wrapped around the base of each penetration, and the tank and penetration MLI butted against it, as recommended in reference [8]. The tank penetrations were wrapped with 15 layers of MLI, again with two Dacron netting spacers used between each Mylar layer.

\section{Broad Area Cooling}

The broad area cooling tubing network consisted of 10 tubes, 5 supply and 5 return that went vertically down the tank wall (see Figure 2). Each tube was $0.64 \mathrm{~cm}(1 / 4 \mathrm{inch})$ tubing with a $0.89 \mathrm{~mm}(0.035 \mathrm{inch})$ wall thickness distributed evenly around the tank. The tubes were spaced 36 degrees apart from each other and were coupled together at the tank top by using two manifolds, $1.3 \mathrm{~cm}$ diameter.

The cooling tubes were epoxied on one side down the length of each tube. In addition, the tubes were spot welded to the tank at every $0.30 \mathrm{~m}$ of tube length. This configuration resulted in a tube-to-tank thermal effectiveness of 0.9 , which was satisfactory. This structural and thermal concept was settled upon after numerous epoxy configurations were tested with LN2, to evaluate the tube epoxy. The epoxy selected was 3M's ScotchWeld 2216. By itself, however, the epoxy did not have enough strength to secure the tube tight to the tank wall, due to contraction of the tank wall at liquid nitrogen temperatures.

\section{Cryocooler}




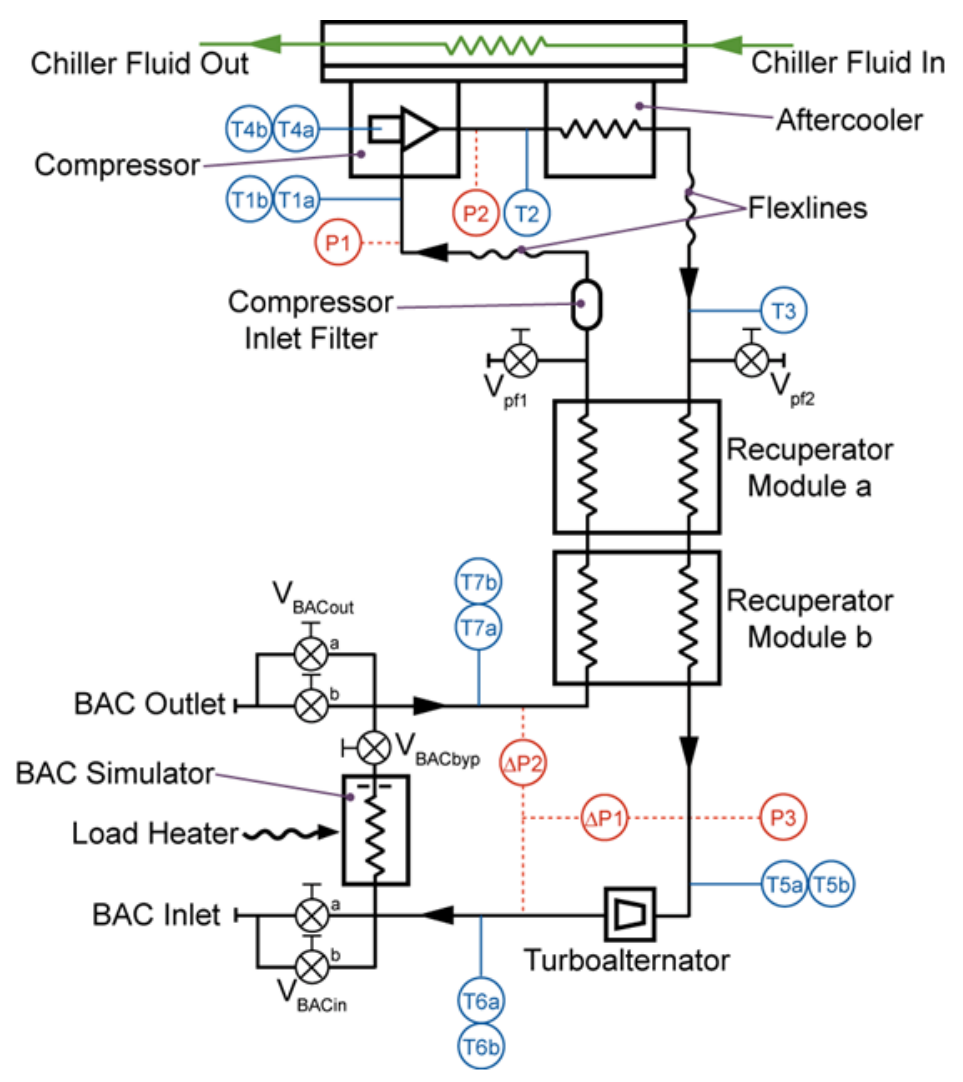

Figure 4. Cryocooler schematic with temperatures $(\mathrm{T})$, pressures $(\mathrm{P})$, and pressure drop $(\Delta \mathrm{P})$ measurements indicated at their respective locations.

The schematic of the reverse turbo-Brayton cryocooler cycle used in the test is shown in Figure 4, with instrumentation. The cycle gas is neon. A single compressor compresses the neon, causing it to flow continuously through the system. The heat of compression and any losses within the compressor are rejected at the radiator mounting plate, which also rejects any losses associated with the electronics. The high-pressure gas flows through both recuperators and then is expanded through the turbo alternator and flows to our broad area cooling system. The cryocooler/circulator is a modification of an existing 2-stage cryocooler [9] that was designed and built by Creare that was originally based on the NICMOS cryocooler used on Hubble Space Telescope. It was modified by (1) eliminating the second-stage turbo-alternator and recuperator; (2) replacing the commercial compressor inlet filter and aftercooler with flight-like versions; (3) altering the compressor flow passages for lower flow rates; and (4) repackaging the cryocooler assembly and reconfiguring the tubing, valves, and fittings to interface with the NASAprovided distributed cooling network. A three-dimensional model of the cryocooler is shown in Figure 5. 


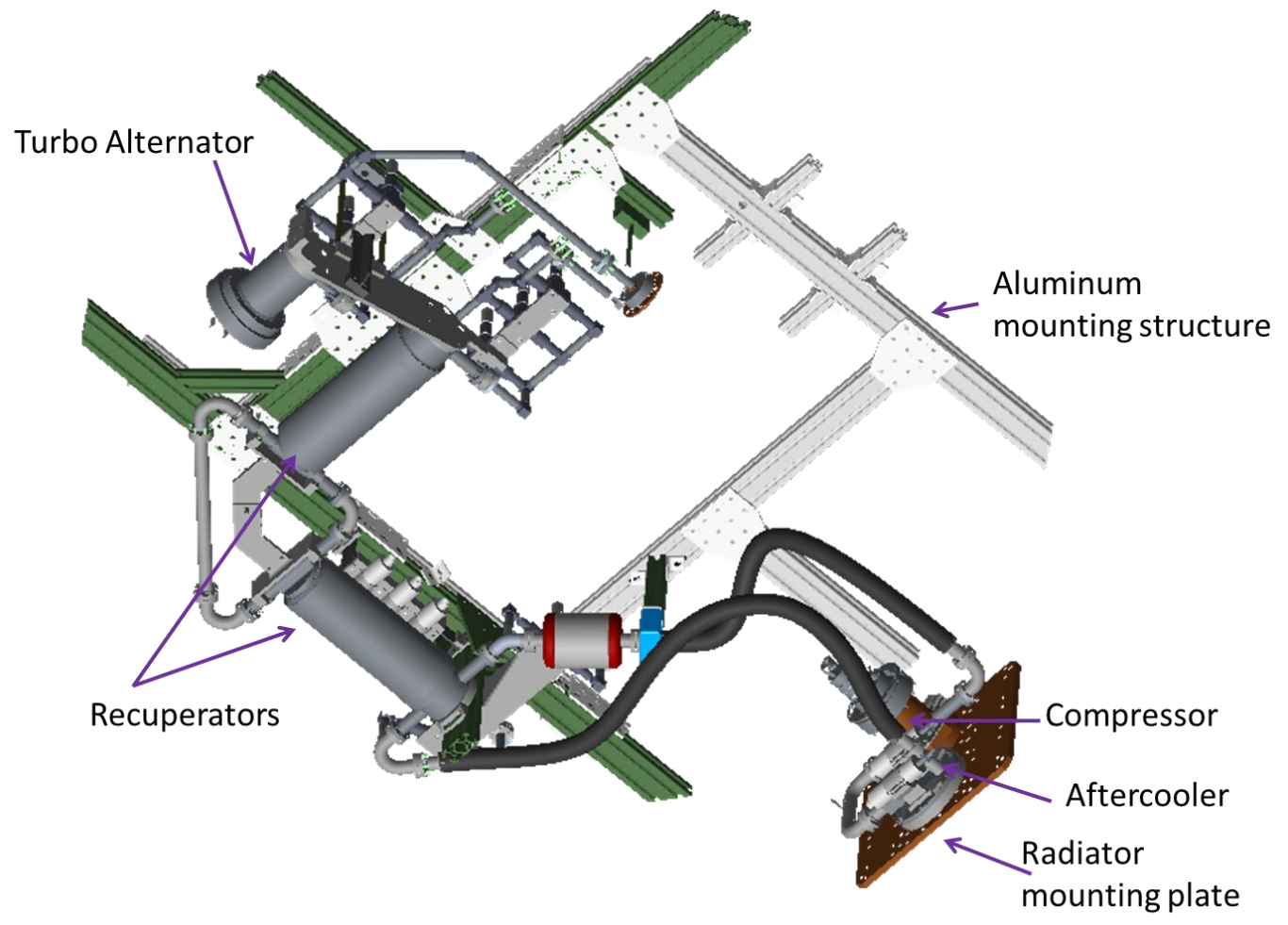

Figure 5. A 3D model of the reverse turbo-Brayton cryocooler assembled into the aluminum channel structure.

The cryocooler's working fluid is neon at $\sim 2 \mathrm{~atm}$, with a nominal flow rate of $2 \mathrm{~g} / \mathrm{s}$. The cooling capacity specified is $15 \mathrm{~W}$ at a load temperature of $77 \mathrm{~K}$, however the lift was over $20 \mathrm{~W}$ at the nominal cryocooler return temperature of $98.4 \mathrm{~K}$, used for the ZBO tests. The cryocooler was operated by setting the return temperature to a user specified value. There was no direct feedback to tank pressure, so the cryocooler temperature set point was finely adjusted until tank pressure was steady. For the pressurization tests, the compressor input power was varied which changed the cryocooler lift from $\sim 3 \mathrm{~W}$ to over $20 \mathrm{~W}$ at neon mass flow rates between $\sim 1.5 \mathrm{~g} / \mathrm{s}$ to $2.5 \mathrm{~g} / \mathrm{s}$.

Heat was generated at the compressor and aftercooler, which are both mounted on a common mounting plate. This plate was thermally coupled to the radiator, where the heat was rejected to the cryoshroud. The design heat rejection temperature of the cryocooler is between 270 and $300 \mathrm{~K}$.

\section{Instrumentation}

The recorded cryocooler data is shown in Figure 6 and includes redundant sensors at the inlet and exit conditions at each main component in the system. The BAC temperatures, T6 and T7, as shown in the schematic, were calibrated platinum resistant thermometry probes $(+/-0.04 \mathrm{~K})$ that measured the neon temperature in the tube. The cryocooler 
system mass flow rate is found from the fluid supply and return conditions of the turboalternator, its rotational speed, and its physical characteristics.

In addition to the cryocooler system, the propellant tank and the rest of the ZBO test article was highly instrumented. Measurements used for conducting the test series included tank pressure, vacuum chamber pressure, tank liquid and wall temperatures, insulation temperatures, cryoshroud temperatures, BAC temperatures, and tank boil-off flow rate. The types of instruments, numbers, and their locations are shown in Table 1. Table 1. ZBO Instrumentation.

\begin{tabular}{|c|c|c|c|}
\hline Location & Count & $\mathrm{SD} / \mathrm{TC}$ & Notes - Purpose \\
\hline $\begin{array}{l}\mathrm{LN}_{2} \text { Temperature } \\
\text { Sensor Rake }\end{array}$ & 8 & $8 / 0$ & $\begin{array}{l}\text { Liquid temperature and liquid level indication. } \\
\text { Key sensors at } 96.9,87.2 \text {, and } 28.4 \% \text { full. }\end{array}$ \\
\hline Tank Wall & 13 & $12 / 1$ & $\begin{array}{l}\text { Exterior tank temperatures at top, bottom, and } \\
\text { between cooling loops. }\end{array}$ \\
\hline BAC System & 28 & $21 / 7$ & $\begin{array}{l}\text { Measure BAC system temperatures (cooling } \\
\text { tubes, manifolds, and thermal strap) }\end{array}$ \\
\hline Penetrations & 16 & $6 / 10$ & $\begin{array}{l}\text { Two at warm and two at cold end of vent, } \\
\text { fill/drain, and cap probe. Used for heat leak } \\
\text { calc's }\end{array}$ \\
\hline Struts & 26 & $2 / 24$ & $\begin{array}{l}\text { Two at warm and two at cold ends. Heat leak } \\
\text { calculations. }\end{array}$ \\
\hline Radiator & 25 & $0 / 25$ & Map radiator performance. \\
\hline MLI & 11 & $0 / 11$ & Determine MLI temperature profile. \\
\hline Supports/cabling & 12 & $0 / 12$ & $\begin{array}{l}\text { Used to find misc. heat leak through wire } \\
\text { bundles \& suspension hardware. }\end{array}$ \\
\hline Cryoshroud & 18 & $0 / 18$ & Boundary temperature definition and control. \\
\hline Tank Pressure & 2 & NA & $\begin{array}{l}\text { Measure and control tank pressure. Range of } \\
\text { sensors were } 0-50 \text { and } 0-100 \text { psia. }\end{array}$ \\
\hline Boil-off Flow & 4 & NA & Mass flowmeters used to measure boil-off rates \\
\hline $\begin{array}{l}\text { Tank/Strut } \\
\text { Heaters }\end{array}$ & 14 & NA & $\begin{array}{l}\text { Warm up tank, warm liquid, and set warm } \\
\text { boundary temperature on struts }\end{array}$ \\
\hline
\end{tabular}

Key-SD refers to a silicon diode; TC is a thermocouple. 


\section{Test Plan}

The test was planned to meet the major test requirements of establishing the baseline heat leak, achieving zero boil-off by controlling tank pressure for an extended period of time, and robustly controlling pressure by dropping tank pressure using the cryocooler. To accomplish this, the test tank was filled with $\mathrm{LN}_{2}$ and then pressurized to $565 \mathrm{kPa}$. This is the saturation pressure when $\mathrm{LN}_{2}$ 's saturation temperature $(95.6 \mathrm{~K})$ is equal to that of $\mathrm{LO}_{2}$ at $172 \mathrm{kPa}$, the nominal pressure fed propulsion system tank supply pressure. Tank sidewall heat was applied to facilitate the pressure rise. The fluid liquid level was set to $\sim 95 \%$ full. The environmental conditions were set using the cryoshroud, which was set to $220 \mathrm{~K}$, a representative low Earth orbit temperature, and the vacuum pumps, which evacuated the chamber to $1 \times 10^{-6}$ torr. These conditions remained constant for the vast majority of the test series.

Two types of tests were conducted, steady state tests and pressurization tests. Steady state tests were as the name applies, performed until the steady state criteria was established, with the most important one being that the MLI temperatures did not vary more than $0.55 \mathrm{~K}$ in a six hour period. Pressurization (including depressurization) tests were performed to understand the tank heating rate effect on tank pressure. Pressurization tests were conducted overnight, to ensure enough time for sufficient pressure variation.

Table 2 shows the tests conducted.

\begin{tabular}{|l|l|l|l|}
\hline & Fill Level & Type & Purpose \\
\hline Test 1 & $95 \%$ & Passive boil-off & Find tank heat leak \\
\hline Test 2 & $95 \%$ & Passive Pressurization & Find tank pressure rise rate \\
\hline Test 3 & $95 \%$ & ZBO & Achieve ZBO; collect data \\
\hline Test 4 & $95 \%$ & ZBO high power & Find robustness of ZBO system \\
\hline Test 5 & $95 \%$ & ZBO low power & $\begin{array}{l}\text { More data to map pressurization rate with } \\
\text { cooler power }\end{array}$ \\
\hline Test 6 & $95 \%$ & ZBO destratification & $\begin{array}{l}\text { Find tank pressure rise rate with tank heat } \\
\text { added while at ZBO }\end{array}$ \\
\hline Test 7 & $95 \%$ & ZBO high power 2 & $\begin{array}{l}\text { More data to map pressurization rate with } \\
\text { cooler power }\end{array}$ \\
\hline Test 8 & $25 \%$ & ZBO & Achieve ZBO; collect data \\
\hline Test 9 & $25 \%$ & ZBO high power & $\begin{array}{l}\text { More data to map pressurization rate with } \\
\text { cooler power }\end{array}$ \\
\hline Test 10 & $95 \%$ & $\begin{array}{l}\text { Passive boil-off with } \\
\text { cryoshroud set to } \\
\text { 300K }\end{array}$ & $\begin{array}{l}\text { Additional MLI data point for tank applied } \\
\text { system }\end{array}$ \\
\hline
\end{tabular}

The cryocooler was operated continuously from Test 3 through Test 9 for 19 days and during that time, the test tank was not vented.

\section{Results}

\section{Summary of Component Performance}


There were several components that were analyzed pre-test for their performance, as shown in Table 3, and are compared here with their actual performance. Also, comments on further needed developments for flight are included.

Table 3 Component Performance

\begin{tabular}{|l|l|l|}
\hline & Pre-Test Analysis & Result \\
\hline BAC Network Temp Increase & $<5 \mathrm{~K} \mathrm{Temp} \mathrm{gradient}$ & $3.8 \mathrm{~K}(\max )$ \\
\hline BAC Pressure Drop & $<4.1 \mathrm{kPa}$ & Not Accurately measured \\
\hline BAC tube-tank Gradient & $0.1 \mathrm{~K}$ & $0.5 \mathrm{~K}$ \\
\hline BAC Effectiveness & $99 \%$ & $90 \%$ \\
\hline Cryocooler \% of Carnot & $10.6 \%$ & $10.6 \%$ \\
\hline Parasitic loss & No model & $4.2 \mathrm{~W}$ (ave) \\
\hline
\end{tabular}

\section{Broad Area Cooling}

The Broad Area Cooling system design performed well. The two main indicators of that were the temperature gradient and pressure drop. The temperature gradient from the exterior tank top to bottom was $3.8 \mathrm{~K}$ in Test 3, a large reduction from Test 1 , where the same gradient was $10.2 \mathrm{~K}$. Also, the pressure drop in the system, $\Delta \mathrm{P} 2$, across the BAC network, was $1.7 \mathrm{kPa}(0.25 \mathrm{psi})$, less than the $4.1 \mathrm{kPa}$ expected. This is for a tubing network that was $4.2 \mathrm{~m}$ long on the tank, plus the manifolds and $1 \mathrm{~m}$ long supply and return hoses. The low thermal gradient from tank top to bottom contrasts dramatically with the 2003 Advanced ZBO Demonstration Test[10], with its "S" link (20 cm long) and heat pipe ( $80 \mathrm{~cm}$ long and submerged in the $\mathrm{LN}_{2}$ tank) coupling of the pulse tube cryocooler to the LN2 tank. That thermal gradient was $6.9 \mathrm{~K}$, which would have increased significantly if the cryocooler was not placed adjacent to the tank.

The tube-to-tank thermal gradient was $0.5 \mathrm{~K}$, higher than the pre-test model indicated. However, the tube-to-tank heat exchanger effectiveness analysis performed, which used the tank fluid, wall, and BAC tube temperatures in its calculations, found the tube-ontank thermal effectiveness was $90 \%$. The effect of this effectiveness on cryocooler input power was found to be minimal, when compared to a $100 \%$ effectiveness. The impact for Test 5, for example, was an increase in cryocooler input power of $0.5 \mathrm{~W}$, a $0.4 \%$ increase. A configuration with a $70 \%$ effective $\mathrm{BAC}$ would require $1.4 \%$ increase in input power.

Besides the outstanding thermal aspect to the BAC, the fluid flow and structural results with a cryogen were also promising. The low thermal gradients also indicate that the fluid flow was evenly distributed through the distributed cooling network that had no trim valves or orifices to even out flow. This indicates that the manifolds effectively distributed the neon gas to each of the five cooling tubes. In addition, the thermal data and the post-test destructive investigation shows that the spot weld and epoxy attachment method worked properly in a system configuration, under vacuum and with cryogenic nitrogen in the tank.

Despite the performance of the BAC tube-on-tank network, further work is needed for a flight application. The design used was developed by bench testing different attachment methods to a large, thick-walled steel pipe, which was then dipped into liquid nitrogen, to 
determine if the tube would separate from the pipe. The next step in flight preparation is a thermal and structural optimization with a flight-weight tank.

\section{Cryocooler}

The cryocooler performed nominally. For Test 3, which had relatively low input power, the cryocooler's efficiency was $10.6 \%$ of Carnot. For Test 4 , the high power test, the cryocooler's efficiency was $12 \%$ of Carnot. Both of these cryocooler efficiencies fall on the curve created in the Creare bench test and are nominal performances for flight cryocoolers operating at these temperatures and heat loads.

The next step for flight preparedness for ZBO cryocoolers is improvements to the cryocooler control system, to develop an algorithm to control tank pressure. It also needs an improved method to operate at a set power level. Such improvements will give the user more flexibility to control tank pressure robustly - to drop pressure in peak power periods and allow it to increase in periods with solar eclipse. If this is done, testing shows that the power can be effectively stored by modulating the tank pressure.

\section{Parasitic Loss}

The average parasitic loss for the test series was quite high at $4.2 \mathrm{~W}$. Post-test studies point to the high temperature and heat leak of the cryocooler return manifold as the primary cause. The average measured emissivity for this Mylar tape was 0.67, much higher than expected. If the tape had been low emissivity tape, with a polished aluminum finish that has an emissivity of 0.03, like that of the double aluminized Mylar used in the tank insulation, along with other improvements, analysis shows the parasitic loss would have dropped to approximately $1.2 \mathrm{~W}$ to $1.5 \mathrm{~W}$. This improves the ZBO system efficiency from $5-9$ to 7.5 to $11 \%$ of Carnot.

Parasitic heat leak estimation for a flight cannot be realistically estimated without a flight configuration and associated thermal model. It is clear from the results of this test that a thermal design minimizing the parasitic loss is mandatory. This requires thorough understanding of MLI performance on the small tubes used in the broad area cooling network. There are few references with data on MLI with small tubes.

\section{Revisiting Test Objectives}

This section will discuss how well the main test objectives were met.

\section{Objective 1: Robust Tank Pressure Control}

Robust tank pressure control was successfully demonstrated in this test series. This was the first ZBO test with a distributed cooling system in which the cryocooler temperature was used to modulate tank pressure. ZBO, cryo storage without venting, was 


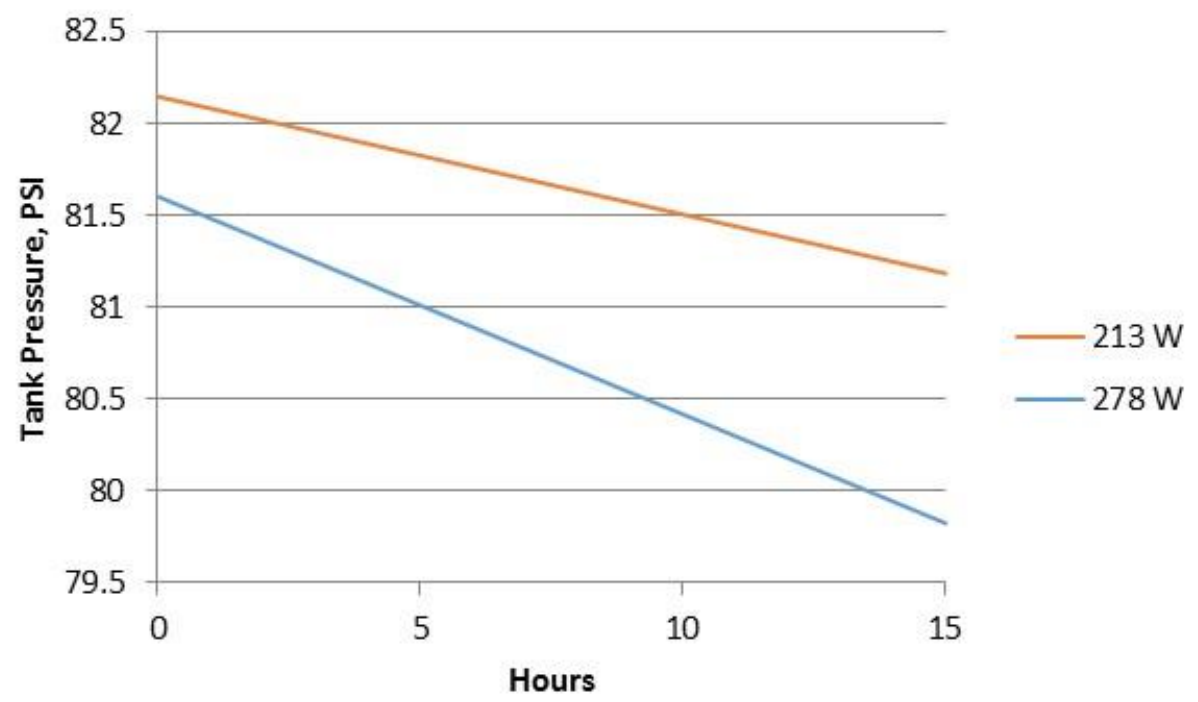

Figure 6. Tank pressure is plotted versus elapsed time at two cryocooler input power settings.

demonstrated over an extended 19 day period. The cryocooler was used to drop tank pressure at two different power settings (see Figure 6). The tank pressure dropped at a rate consistent with that predicted by a uniform temperature pressurization model.

Effectively, the propellant tank was used like a battery, to store power. This could be very useful for in-space operation which will experience regular solar eclipses.

Additionally, the pressurization of a passive tank with no powered cryocooler (Test 2) was compared with the pressurization of an actively cooled ZBO tank with heat added (Test 6). For approximately the same duration, Test 2 tank pressure increased $36.2 \mathrm{kPa}$ while Test 6 tank pressure increased just $1.3 \mathrm{kPa}$. Adjusted per Watt of tank heat leak, the rate of pressurization for Test 2 is 0.58 while Test 6 is $0.067 \mathrm{kPa} / \mathrm{hr} / \mathrm{W}$. That is, the pressure rise rate of an effectively de-stratified cryogen is just $12 \%$ of the stratified fluid.

\section{Objective 2: ZBO at Low Fill Level}

The cryocooler system was also used to achieve ZBO after a tank drain to approximately $25 \%$ full. This fill level, which causes increased thermal stratification due to the larger ullage space, will occur in-space for any cryogenic propellant stage that undergoes multiple engine burns or for a propellant depot after multiple propellant transfers to cryogenic upper stages. This increased stratification cause tank pressurization rates to increase, leading to more frequent vent cycles and increased boil-off losses. However, the cryocooler broad area cooling system kept the tank top temperatures from increasing significantly, from 98.7 at high fill level to just $98.9 \mathrm{~K}$ during the low fill level test. These temperatures were much lower than Test 1 , when the tank top temperature was $105.2 \mathrm{~K}$.

The input power required to maintain steady state $\mathrm{ZBO}$ at this fill level was $145.9 \mathrm{~W}, 0.9$ $\mathrm{W}$ higher than that in Test 3, a very slight increase. The BAC design proved to be more than adequate at reducing the tank top temperatures to keep the tank at ZBO. Also, it 


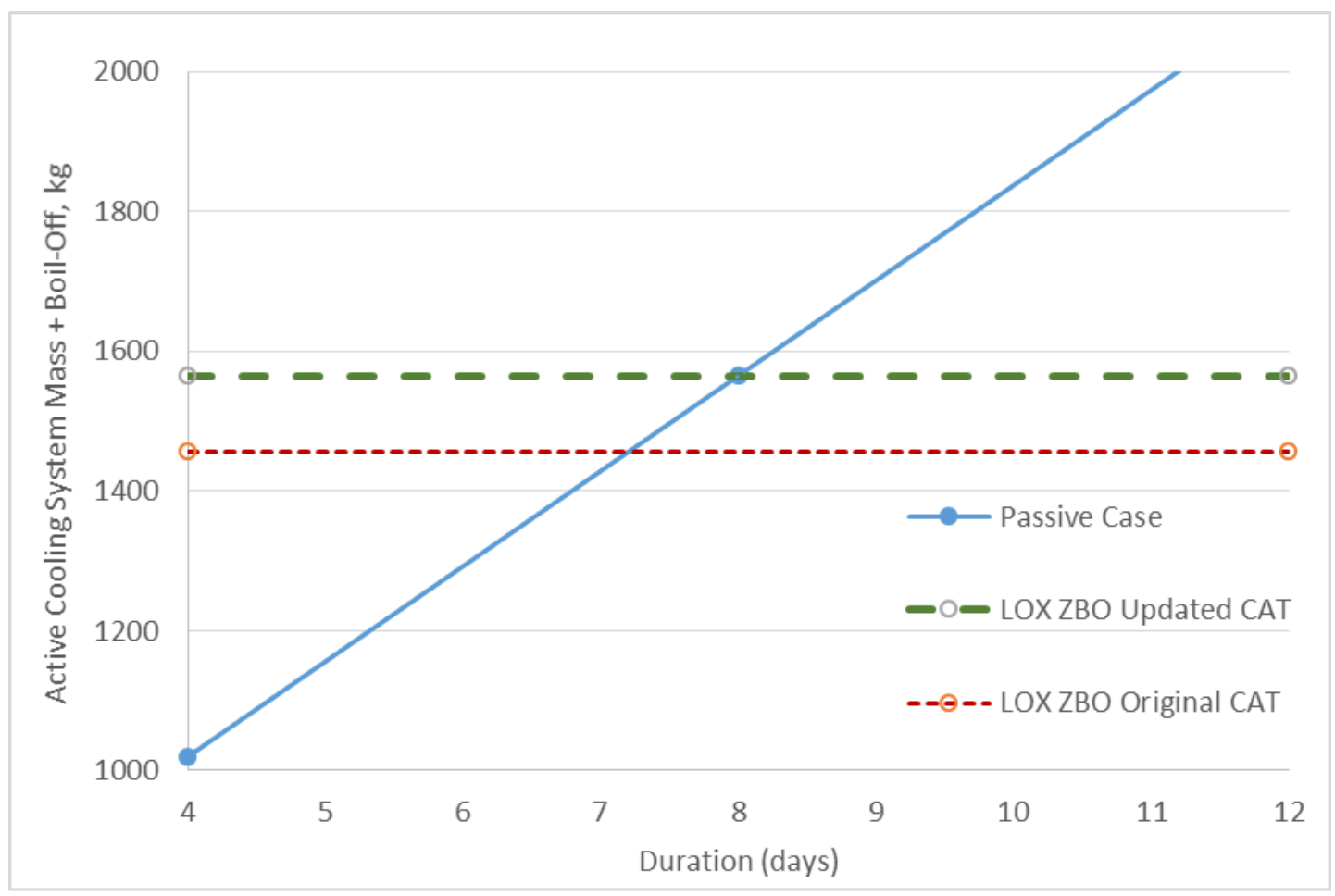

Figure 7. Thermal system mass comparison.

appears that the vent line cooling strap, included to keep tank lid temperatures low, was not needed. The heat removed by it was less than its design and the temperatures it saw were less than expected. Thus, the low fill level storage test requirement did not pose a significant challenge to the active cooling system.

\section{Objective 3: Validation of Scaling Study}

In the Scaling Study [5], an Excel based Cryogenic Analysis Tool (CAT) was created to predict cryogenic thermal control system performance and to estimate the in-space loiter time at which active thermal control mass is equal to the passive thermal control mass, including tank boil-off losses for liquid oxygen propellant tank storage. Following the LOX ZBO tests and an analysis of the results CAT was updated using the design data and the thermal system mass comparison was revisited. It was found that for a full scale 7.5 $\mathrm{m}$ diameter $\left(182.6 \mathrm{~m}^{3}\right)$ liquid oxygen tank with a nominal heat leak of 318 watts (through 75 layers of traditional MLI, structure, and penetrations), that the cryocooler system dry mass increased $6.5 \%$ from our initial estimates, with the difference in total thermal control system mass being $95 \mathrm{~kg}$ (out of $1456 \mathrm{~kg}$ ). The updated model shifted the mass breakeven in space loiter duration point from 7.2 to 8.0 days (see figure 7). Mission durations longer than this should have this ZBO concept in their trade studies for consideration. This shows that, although additional heat is added to the system due to parasitic and integration losses that were not accounted for in previous versions, the turbo-Brayton cryocooler system mass does not significantly increase, lending support to the scalability of the LOX ZBO test concept. 


\section{LOX ZBO Test Summary}

The LOX ZBO test was the first of its kind that demonstrated robust tank pressure control using the cryocooler system to maintain and drop tank pressure without venting. The tank pressure was maintained without venting for a 19 day period. The tank stratification, which causes highly increased tank pressurization rates for unvented and unmixed cryogenic tanks, was cut by $88 \%$ using the broad area cooling system, adjusted for tank heating rate. Robust tank pressure control was also demonstrated at a low fill level, which causes additional tank stratification. In this test, the broad area cooling system minimized tank and fluid temperatures increases and ZBO was achieved with virtually the same cryocooler input power as that at a high fill level. The tube-on-tank broad area cooling system effectively prevented thermal stratifications within the tank while being external to the tank and without introducing parasitic heat loads to the tank. Because of these results, it is clear that an internal tank mixer, with its associated heat and inherent risk to configurations with cryogenic propellants, is not required when the active cooling system is operational.

The full ability of the cryocooler system was demonstrated. Tank pressure was controlled to within +/- 0.1 psi using the active cooling system. Also, tank pressure was decreased at controlled rates with the cryocooler operating at different levels of excess capacity. This variation of the cryocooler's input power and its ability to drop cryogenic propellant tank pressure could reduce or eliminate the cryocooler stored input power requirement, assuming solar arrays provide the power. Batteries are typically required due to solar eclipses occurring during orbits in low Earth orbit.

The thermal results of the test series have been used to validate the scaling study analysis, which has predicted large mass savings for applying ZBO for cryogenic upper stages or depots exposed to long loiter periods in low Earth orbit. While the test found that parasitic losses increase the cryocooler system mass and the passive to ZBO break-even point was slightly longer, the many assumptions of the broad area cooling system and the reverse turbo-Brayton cycle operation used in the modeling effort were confirmed.

For a potential flight application, this test series has advanced the technology significantly, reducing the risk for future flight projects. The documented integrated performance of four main components coupled to a cryogenic tank has increased the confidence of this concept for flight. Work remains, particularly on optimizing the tubeon-tank design and cryocooler integration parasitic design and analysis.

\section{Acknowledgements}

This work was funded and managed by NASA's Space Technology Mission Directorate under the Cryostat program. 
Bibliography:

[1] Mars Architecture Steering Committee, "Human Exploration of Mars Design Reference Architecture 5.0," NASA/SP-2009-566, page 3, 2009.

[2] D. W. Plachta, R. Christie and J. Feller, "Cryogenic Boil-Off Reduction System," AIP, New York, 2008.

[3] J. R. Feller, L. Salerno, A. Kashani and B. Helvenstein, "Distributed Cooling Techniques for Cryogenic Boil-Off Reduction Systems," Kluwer Academic/Plenum Publishers, New York, 2009.

[4] J. R. Feller, D. W. Plachta, G. Mills and C. McClean, "Demonstration of a Cryogenic Boil-Off Reduction System Employing an Actively Cooled Thermal Radiation Shield," Kluwer Academic/Plenum Publishers, New York, 2010.

[5] D. Plachta, "Cryogenic Boil-Off Reduction System Scaling Study," Elsevier, www.elsevier.com/locate/cryogenics, 2014, Vol. 60, pages 62-68.

[6] J. Jurns and M. Kudlac, "NASA Glenn Research Center Creek Road Complex," Cryogenics Vol. 46, Pages 98-104, Elsevier, New York, 2006.

[7] "Lydall Performance Materials, Cryogenic Products, Cryo-Lite Technical Data Sheet," 2011. [Online]. Available: http://www.lydallthermal.com/what/CryogenicProducts.shtml. [Accessed July 2015].

[8] W. Johnson and A. Kelly, "Two Dimensional Heat Transfer around Penetrations in Multilayer Insulation," NASA TP 2012-216315, page 50, 2012.

[9] M. Zagarola, "Demonstration of a Two-Stage Turbo-Brayton Cryocooler for Space Application," Kluwer Academic/Plenum , Cryocoolers 15, New York, 2009.

[10] D. Plachta, "Results of an Advanced Development Zero Boil-Off Cryogenic Propellant Test," NASA TM 2004-213390, 2004. 